\title{
Protection against Noise-Induced Hearing Loss in Young CBA/J Mice by Low-Dose Kanamycin
}

\author{
Elizabeth A. Fernandez ${ }^{1}$, Kevin K. Ohlemiller ${ }^{1,2}$, Patricia M. Gagnon ${ }^{2}$, and William W. Clark ${ }^{1,2}$ \\ ${ }^{1}$ Program in Audiology and Communication Sciences, Washington University School of Medicine, St. Louis, MO 63110, USA \\ ${ }^{2}$ Fay and Carl Simons Center for Biology of Hearing and Deafness, Department of Otolaryngology, Washington University School \\ of Medicine, 660 S. Euclid, St. Louis, MO 63110, USA
}

Received: 23 July 2009; Accepted: 9 December 2009; Online publication: 22 January 2010

\begin{abstract}
Animal studies indicate that a combination of kanamycin $(\mathrm{KM})$ and noise produces a synergistic effect, whereby the threshold shift from the combination is greater than the sum of the shifts caused by either agent alone. Most such studies have focused on adult animals, and it has remained unclear whether younger, presumably more susceptible, animals show an even greater synergistic effect. The present study tested the hypothesis that young $\mathrm{CBA} / \mathrm{J}$ mice receiving a low dose of $\mathrm{KM}(300 \mathrm{mg} / \mathrm{kg}$, $2 \times /$ day, s.c.) from 20 to 30 days post-gestational age followed by brief noise exposure (110 dB SPL; 4-45 kHz, $30 \mathrm{~s}$ ) would show greater noise-induced permanent threshold shifts (NIPTS) than mice receiving either treatment alone. Noise exposure produced $30-40 \mathrm{~dB}$ of NIPTS and moderate hair cell loss in young saline-treated mice. KM alone at this dose had no effect on thresholds. Surprisingly, mice receiving KM plus noise were protected from NIPTS, showing ABR thresholds not significantly different from unexposed controls. Mice receiving KM prior to noise exposure also showed significantly less outer hair cell loss than saline-treated mice. Additional experiments indicated protection by KM when the noise was applied either 24 or $48 \mathrm{~h}$ after the last KM injection. Our results demonstrate a powerful protective effect of subchronic low-dose kanamycin against NIPTS in young $\mathrm{CBA} / \mathrm{J}$ mice. Repeated kanamycin exposure may establish a preconditioned protective state, the molecular bases of which remain to be determined.
\end{abstract}

Keywords: ototoxicity, preconditioning, aminoglycosides, cochlea, hair cells, development

Correspondence to: Kevin K. Ohlemiller · Fay and Carl Simons Center for Biology of Hearing and Deafness, Department of Otolaryngology - Washington University School of Medicine $\cdot 660$ S. Euclid, St Louis, MO 63110, USA. Telephone: +1-314-7477179; fax: +1-3147477230; email: kohlemiller@wustl.edu

\section{INTRODUCTION}

The estimated incidence of clinically significant bilateral hearing loss in infants has been estimated at one per 500 live births (Mehl and Thomson 1998). Events that occur in the early days of life, including exposure to ototoxic antibiotics and/or noise, may result in an acquired hearing loss that is labeled congenital. Medically fragile neonates often receive antibiotics and may experience noise peaks of up to $125 \mathrm{~dB}$ SPL during emergency transport via aircraft (Skeoch et al. 2005; Shenai 1977; Buckland et al. 2003). This practice has remained, even though human neonates may be particularly susceptible to noise, ototoxins, and their combination (Henley and Rybak 1995; Bernard 1981; Li and Steyger 2009). Presently, the risk of noise-induced permanent threshold shifts (NIPTS) to human infants is largely uncharacterized.

An early window of heightened vulnerability to both noise and a wide variety of ototoxicants is well supported by animal studies (e.g., Pujol 1992; Bombard et al. 2005; Bernard 1981; Lataye et al. 2004; Rybak et al. 1991; Henley and Rybak 1995; Pryor et al. 1984). Cochlear targets most affected during this window include hair cells, neurons, and stria vascularis. Thus, no special susceptibility of any single structure or cell type can provide a complete explanation. Animal studies also support synergistic interaction between noise and ototoxins, at least in adults (e.g., Dayal et al. 1971; Dayal and Barek 1975; Marques et al. 1975; Hawkins et al. 1975; Ryan and Bone 1978; Brown et al. 1980; Brummett et al. 1992). Most of these applied high levels of noise and ototoxins. However, Brummett et al. (1992) identified a synergistic effect between subclinical doses of white noise (as low as $75 \mathrm{dBA}$ ) and kanamycin (300 $\mathrm{mg} / \mathrm{kg}$ ) on hair cell loss in adult guinea pigs. It has remained 
unclear to date whether such synergy extends to neonates or is perhaps even more pronounced in neonates (Humes 1984; Henley and Rybak 1995; Li and Steyger 2009).

Here, we explore the interaction of sub-chronic, low-dose kanamycin (KM) and damaging noise using young (post-wean) CBA/J inbred mice as a model. The laboratory mouse is a well-established model for human auditory conditions, as it possesses similar cochlear anatomy and physiology and similar patterns of age-related, noise-induced, and ototoxicity-related hearing loss (Ohlemiller 2006; Wang and Steyger 2009; Wu et al. 2001; Henry and McGinn 1992). Among inbred strains, $\mathrm{CBA} / \mathrm{J}$ mice are frequently used as a "good hearing" strain that is resistant to ageassociated pathology. Like other animals and humans, young mice are especially susceptible to NIPTS (Henry 1983; Ohlemiller et al. 2000). Noise vulnerability in mice appears greatest during the first month then gradually decreases up to about 4 months of age (Henry 1983). Young mice also show greater susceptibility to ototoxins (Henry et al. 1981; Chen and Aberdeen 1980; Chen and Saunders 1983). Similar to the pattern for noise, vulnerability to aminoglycosides in mice appears maximal during the first month. After 1 month, it can be difficult to elicit ototoxic injury in mice without co-administration of ethacrynic acid or furosemide (Wu et al. 2001; Taylor et al. 2008). In keeping with the literature, we hypothesized that young mice would show stronger KM plus noise synergistic effects on hearing than have been reported in adult animals. As we show, the nature of the interaction was surprisingly one of prevention of NIPTS, not potentiation.

\section{METHODS}

\section{Animals}

Our study population included a total of 59 postweanling $\mathrm{CBA} / \mathrm{J}$ mice. All experimental groups included both genders. Most mice were bred from in-house breeding pairs, while a few of the animals were obtained directly from The Jackson Laboratory. Mice were assigned to one of seven primary experimental groups (Table 1) that included: No treatment, Noise alone, KM alone, KM plus noise, and Saline plus noise. An additional control group including mice that received the standard KM regimen but underwent ABR testing at the time noise exposure would have occurred. These mice served to detect any threshold elevation due to KM at the time of noise exposure. Another control group tested the effects of single dose of $\mathrm{KM}(300 \mathrm{mg} / \mathrm{kg})$ administered $1 \mathrm{~h}$ prior to noise. These were intended to differentiate between the effects of a repeated KM dosing regimen versus a single dose. Finally, two smaller experimental groups tested the effects of KM on NIPTS when noise exposure was delayed by 24 or $48 \mathrm{~h}(N=4 \mathrm{each})$ after the last KM dose. All procedures were approved by the Animal Studies Committee at Washington University School of Medicine.

\section{Kanamycin injections}

Mice receiving kanamycin sub-chronically were injected subcutaneously twice daily at $300 \mathrm{mg} / \mathrm{kg}$ for 11 days $(63.93 \mathrm{mg} / \mathrm{ml} \mathrm{KM}$ in $0.9 \%$ saline). Injections began at 20 days post-gestational age (PGA) and ended at 30 days PGA. Mice were weighed prior to each injection. Injections occurred at 12-h intervals. The drug regimen was well-tolerated, and no mice were lost during the course of treatment. Mice in the saline treatment group received an equivalent volume of saline using the same injection regimen.

\section{Noise exposure}

At 30 days PGA, mice were exposed to $30 \mathrm{~s}$ of broadband noise ( 4 to $45 \mathrm{kHz}$ ) at $110 \mathrm{~dB}$ SPL. Noise was produced and filtered with General Radio 1310 generators and Krohn-Hite 3550 filters, respectively. Groups of two or three animals were placed in a wired cage suspended between four speakers at $0^{\circ}, 90^{\circ}$,

\section{TABLE 1}

\begin{tabular}{lcccccc}
\hline \multicolumn{5}{c}{ Average ABR thresholds by experimental group at each test frequency } \\
\hline \multicolumn{1}{c}{ GROUP } & Number & $5 \mathrm{kHz}$ & \multicolumn{1}{c}{$10 \mathrm{kHz}$} & $20 \mathrm{kHz}$ & $28.3 \mathrm{kHz}$ & $40 \mathrm{kHz}$ \\
\hline No treatment & 9 & $41.44(4.64)$ & $23.56(4.64)$ & $31.67(7.91)$ & $32.11(6.51)$ & $38.33(8.29)$ \\
Noise alone & 9 & $68.11(18.67)$ & $58.56(20.07)$ & $64.44(24.30)$ & $73.78(27.05)$ & $90.00(22.91)$ \\
KM alone ABR 10 days post noise & 9 & $39.22(3.63)$ & $22.44(1.67)$ & $25.56(3.00)$ & $31.00(5.00)$ & $36.25(9.71)$ \\
KM alone ABR same day & 8 & $40.13(5.30)$ & $24.88(2.59)$ & $31.63(6.78)$ & $32.50(4.63)$ & $40.63(4.17)$ \\
KM + Noise & 8 & $42.63(6.23)$ & $22.38(4.17)$ & $30.63(4.96)$ & $34.13(4.58)$ & $53.13(19.45)$ \\
Saline + Noise & 7 & $67.00(15.28)$ & $63.71(17.42)$ & $66.00(18.25)$ & $75.71(7.32)$ & $82.86(6.36)$ \\
1 dose KM + Noise & 9 & $68.11(17.81)$ & $57.44(21.28)$ & $69.00(15.90)$ & $80.89(6.62)$ & $93.33(8.29)$ \\
\hline
\end{tabular}

Standard deviations in parentheses 
$180^{\circ}$, and $270^{\circ}$ azimuth in a single-walled soundproof booth with foam treatment (Industrial Acoustics, Bronx, NY). The cage was rotated at approximately $0.013 \mathrm{~Hz}$ during the exposure to achieve a homogeneous sound field. For all noise groups except the group receiving a single $\mathrm{KM}$ dose, the noise exposure was initiated $15 \mathrm{~min}$ following the final dose of kanamycin or saline. This interval was based on previous pharmacokinetic analyses of subcutaneous kanamycin injections in mice showing peak serum levels at approximately 15 min post-injection and an elimination half-life of $1 \mathrm{~h}$ (Wu et al. 2001).

\section{ABR recording}

Because of the fragility of post-weaning mice at the time of initial treatment, our study design called for a single ABR recording in each animal following all other procedures. Thus, ABR thresholds, not threshold shifts, were compared by treatment group. For most groups, ABR recording was carried out 9-11 days post-treatment (39-41 days PGA) using Tucker-Davis Technologies (TDT) System II hardware and software. Animals were anesthetized with a solution of ketamine and xylazine $(80 / 15 \mathrm{mg} / \mathrm{kg}$, i.p.) and positioned dorsally in a custom headholder. Subdermal platinum needle electrodes (Grass) were placed in the midback (ground), behind the right pinna (active), and at the vertex (reference). Body temperature was monitored throughout testing using a rectal probe and maintained at $37.5 \pm 1.0^{\circ} \mathrm{C}$ using a DC currentbased isothermal pad (FHC). The right ear of each mouse was stimulated in freefield using a TDT ES-1 speaker placed placed at $7 \mathrm{~cm}$ distance along the interaural axis. Stimuli were $5 \mathrm{~ms}$ tonebursts $(1,000$ repetitions, $20 / \mathrm{s}, 1.0 \mathrm{~ms}$ rise/fall time) at frequencies of $5,10,20,28.3$, and $40 \mathrm{kHz}$. To eliminate contributions to the ABR by the unstimulated ear, the left external meatus was compressed using a spring-loaded clip. Responses were amplified $\times 100,000$ and filtered at $100-10,000 \mathrm{~Hz}$. Wave I of the ABR is considered to be generated by auditory nerve activity and is the most robust wave of the mouse ABR (Zheng et al. 1999). Thresholds were taken to be the lowest sound level for which Wave I could be identified, using a 5-dB minimum step size. Threshold differences by group were analyzed by twoway ANOVA (threshold by treatment, frequency) followed by Bonferroni multiple comparisons tests.

\section{Tissue preparation and analysis}

Cochleas of mice from two experimental groups, KM + Noise and Saline + Noise $(N=7$ each), were prepared for histological analysis after recording. Animals were overdosed using Pentobarbital and perfused transcardially with cold $2.0 \%$ paraformaldehyde/ $2.0 \%$ glutaraldehyde in $0.1 \mathrm{M}$ phosphate buffer (pH 7.4). Each cochlea was rapidly isolated and immersed in the same fixative, and the stapes was removed. Complete infiltration of the cochlea by fixative was facilitated by drilling a small hole at the apex of the cochlear capsule and gently circulating the fixative over the cochlea using a transfer pipet. After decalcification in sodium EDTA for $72 \mathrm{~h}$, cochleas were post-fixed in buffered $1 \%$ osmium tetroxide, dehydrated in an ascending acetone series, and embedded in Epon.

\section{Qualitative light microscopy}

Left cochleas were sectioned in the mid-modiolar plane at $4.0 \mu \mathrm{m}$ then stained with toluidine blue for bright field viewing with a Nikon Optiphot ${ }^{\mathrm{TM}}$ light microscope using a $\times 100$ oil objective and a calibrated grid ocular. Typically 50 sections were obtained from each cochlea, spanning $200 \mu \mathrm{m}$ centered on the modiolar "core."

\section{Hair cell counts}

Right cochleas were dissected using fine blades into half-turn segments, immersed in mineral oil in a depression slide, and examined as surface preparations by Nomarski optics using a $\times 20$ oil objective and a calibrated grid ocular. The percent outer hair cells (OHCs) and inner hair cells (IHCs) missing (as judged by the absence of nuclei) was estimated in contiguous $200 \mu \mathrm{m}$ segments, and data were recorded separately by cell type as a function of distance from the basal tip. For each hair cell type, distance versus percent present was plotted as a function of frequency based on Muller et al. (2005). Hair cell survival differences by group were analyzed by two-way ANOVA (cell loss by treatment, cochlear place), followed by Bonferroni multiple comparison tests.

\section{RESULTS}

\section{ABR thresholds}

Figure 1 shows ABR thresholds for the primary comparison groups. Nine to 11 days after noise exposure, mice receiving noise alone or saline plus noise showed nearly identical threshold shift profiles versus untreated controls, namely a 30-40-dB NIPTS at most test frequencies. By contrast, mice receiving KM plus noise exhibited thresholds that were statistically indistinguishable from untreated controls. There is some indication (not significant) of threshold elevation at $40 \mathrm{kHz}$ in the KM-treated mice.

Administration of $\mathrm{KM}$ produced no threshold elevation, either at the time of noise exposure or 


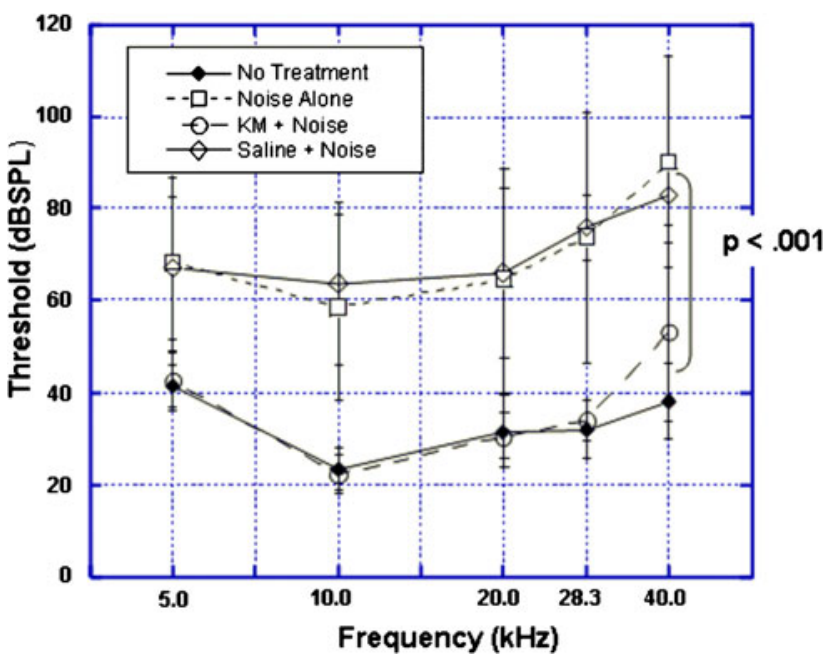

FIG. 1. Mean $( \pm \mathrm{SD}) \mathrm{ABR}$ thresholds for mice receiving either No Treatment, Noise Alone, KM + Noise, or Saline + Noise. Mice receiving Saline + Noise showed significantly elevated ABR thresholds versus unexposed controls (two-way ANOVA). Thresholds in saline-treated mice were not significantly different from the Noise Alone group. Mice receiving KM + Noise showed ABR thresholds not significantly different from the unexposed controls.

10 days after the final KM dose (Fig. 2). This suggests that (1) KM alone at the dose used was not toxic (see below) and (2) the apparent protective effects of KM were not linked to acute threshold elevation that could have reduced sensitivity to the noise exposure. A single dose of $\mathrm{KM}$ administered $1 \mathrm{~h}$ prior to noise was not protective, as NIPTS in these mice was similar to the effect of noise alone (Fig. 3). This indicated that an endogenous response to $\mathrm{KM}$, not merely its acute presence, was required for protection.

We did not explicitly test for the minimal KM dosing regimen that produces protection. However, two smaller

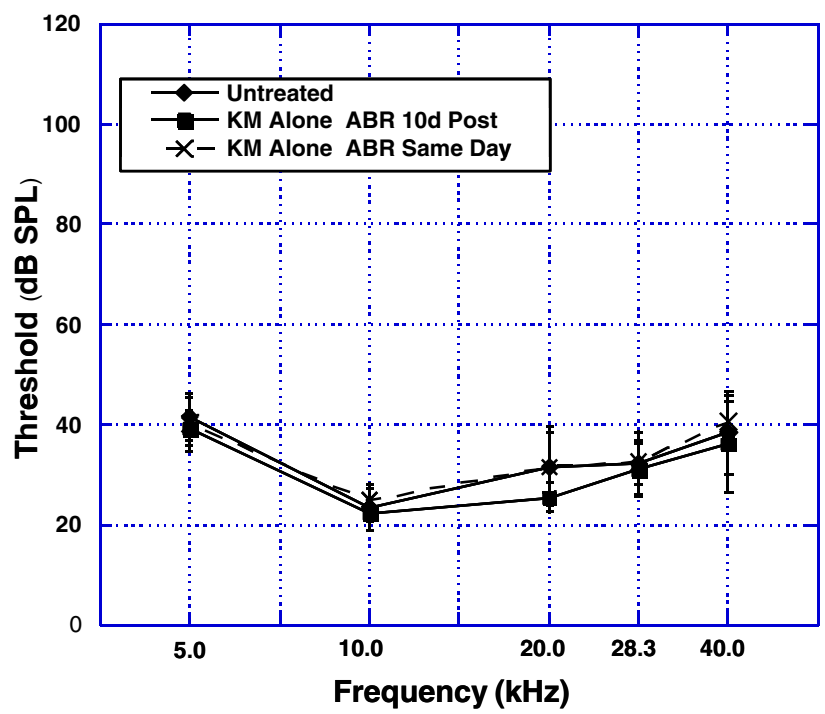

FIG. 2. Mean $( \pm S D) A B R$ thresholds for mice receiving Kanamycin followed by $A B R$ testing either at the time noise would normally have occurred, or 10 days post-treatment. ABR thresholds for either group were not significantly different from untreated controls.

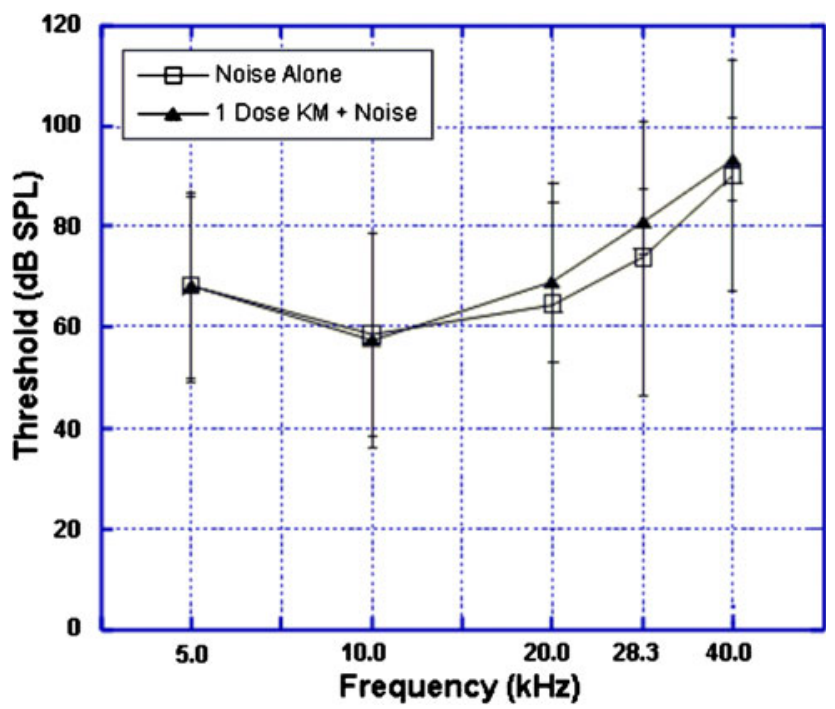

FIG. 3. Mean $( \pm \mathrm{SD})$ thresholds for mice receiving a single kanamycin injection $1 \mathrm{~h}$ prior to noise exposure. These mice had $A B R$ thresholds that were not significantly different from those receiving Noise Alone, indicating that a single KM injection was not effective.

groups examined the protection afforded by $\mathrm{KM}$ when noise was applied either $24(N=4)$ or $48 \mathrm{~h}(N=4)$ after the last dose. As Figure 4 shows, the additional delay showed no diminishing effect on the protection. These data argue that KM produces a "protected state" lasting at least up to 2 days after final application.

\section{Histologic findings}

The pronounced threshold differences by treatment across all test frequencies led us to seek the histologic

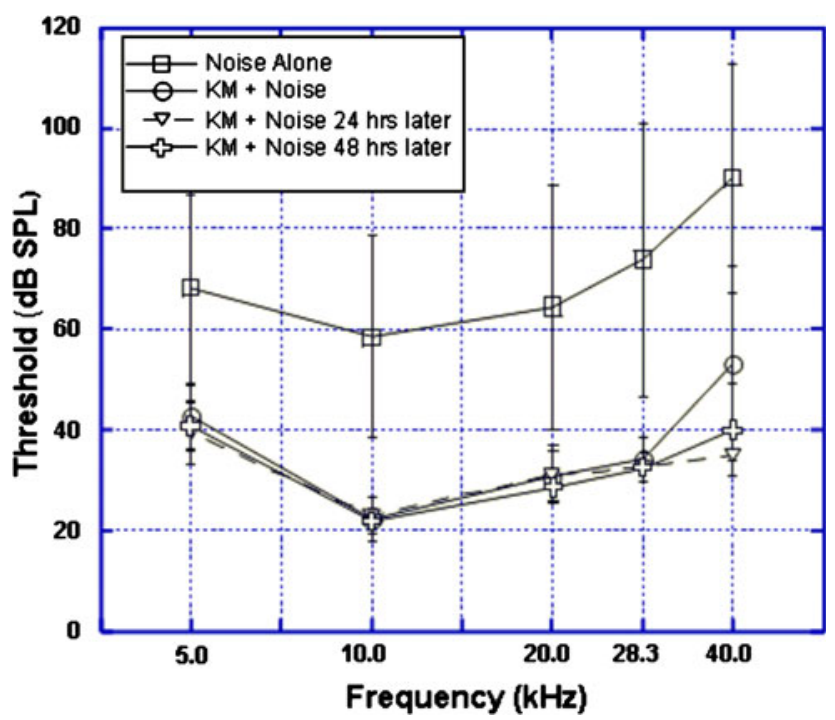

FIG. 4. Mean $( \pm S D)$ ABR thresholds for mice receiving $K M$ followed by noise either 24 or $48 \mathrm{~h}$ later. Thresholds for these animals were indistinguishable from those in the original KM + Noise group. The window for full protection against NIPTS thus extends to at least $48 \mathrm{~h}$ following the final kanamycin injection. 
correlates of injury and protection. Comparison by light microscopy of mid-modular sections from $\mathrm{KM}+$ Noise and Saline + Noise animals yielded no obvious differences in the composition of the lateral wall, neuronal survival, or the condition of the organ of Corti, either in cochlear upper basal turn (Fig. 5) or more apically. In the lower base, however, profiles of the organ of Corti were often devoid of hair cells in saline-treated mice, but not in KM-treated mice
(Fig. 6). Hair cell counts confirmed significant preservation of OHCs in the basal half of the cochlea of KM-treated mice (Fig. 7). Outer hair cell loss in saline-treated controls extended approximately $2.6 \mathrm{~mm}$ from the basal tip. According to the place map published for CBA/J (Muller et al. 2005), this would correspond to frequencies above $14 \mathrm{kHz}$, so that hearing losses at $20,28.3$, and $40 \mathrm{kHz}$ in the saline controls (Fig. 1) appeared explained by OHC

\section{Upper Basal Turn \\ Saline + Noise \\ KM + Noise}
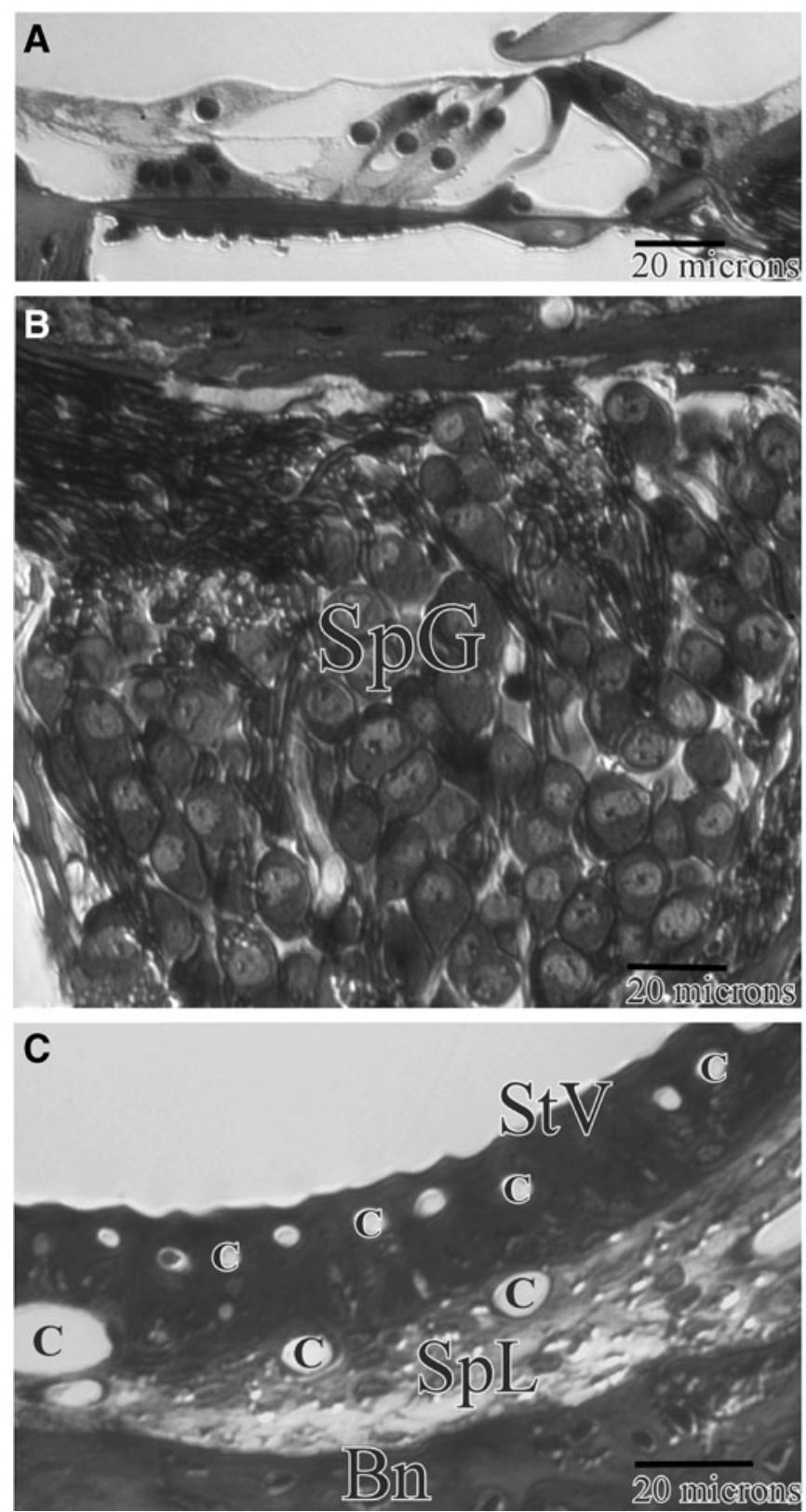
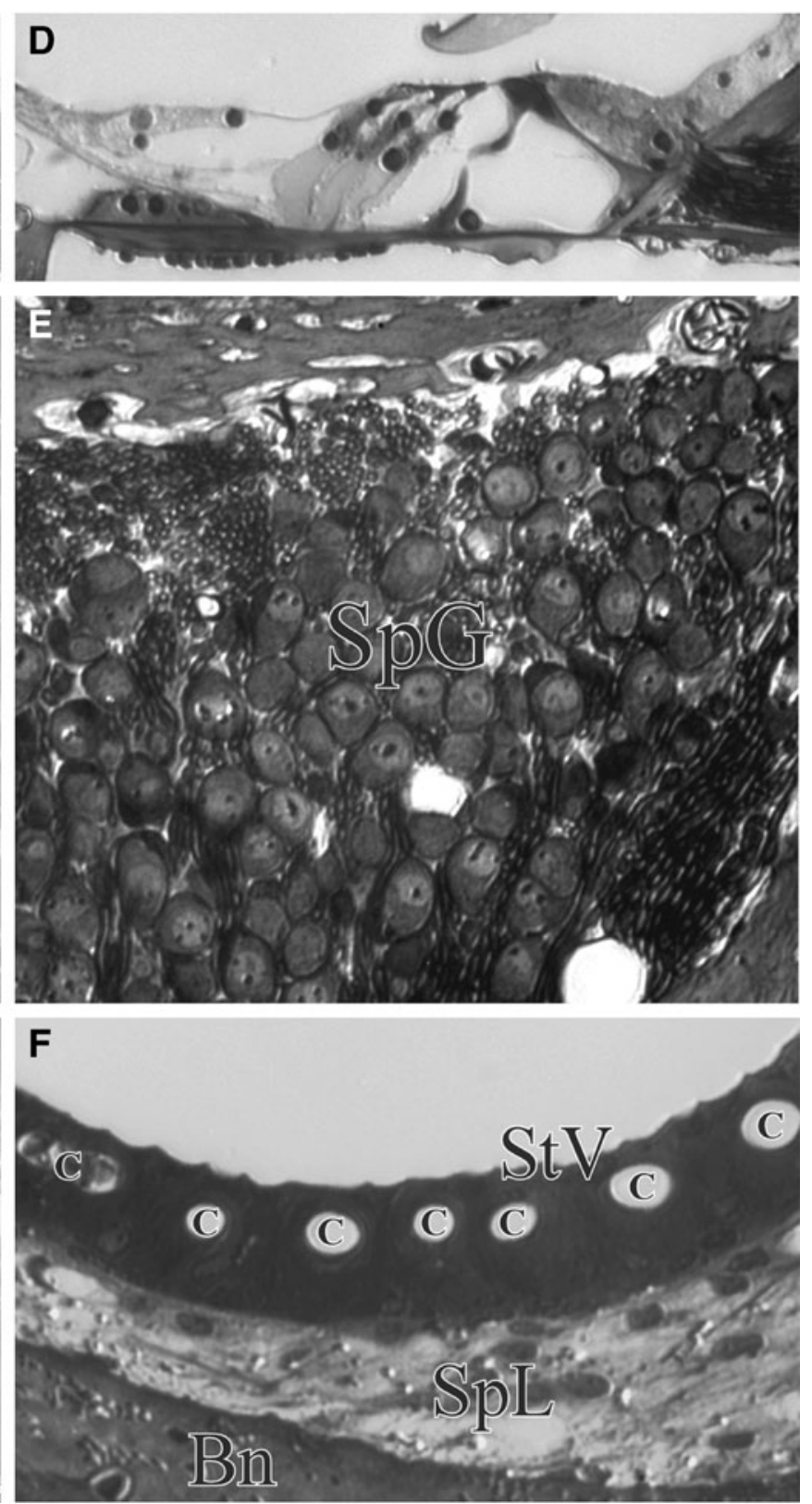

FIG. 5. Light photomicrograph of the cochlear upper base ( $18 \mathrm{kHz}$ region) in two example mice receiving Saline + Noise $(\mathbf{A}-\mathbf{C})$ or KM + Noise $(\mathbf{D}-\mathbf{F})$. No features clearly and consistently distinguished mice by treatment group; Organ of Corti (A, D), spiral ganglion cells ( $\operatorname{SpG}$ in B, E), and lateral wall (C) F) appeared similar in each group. Raised particles in C, F are processing artifacts. StV Stria vascularis; SpL spiral ligament; $C$ capillaries; $B n$ bone. 


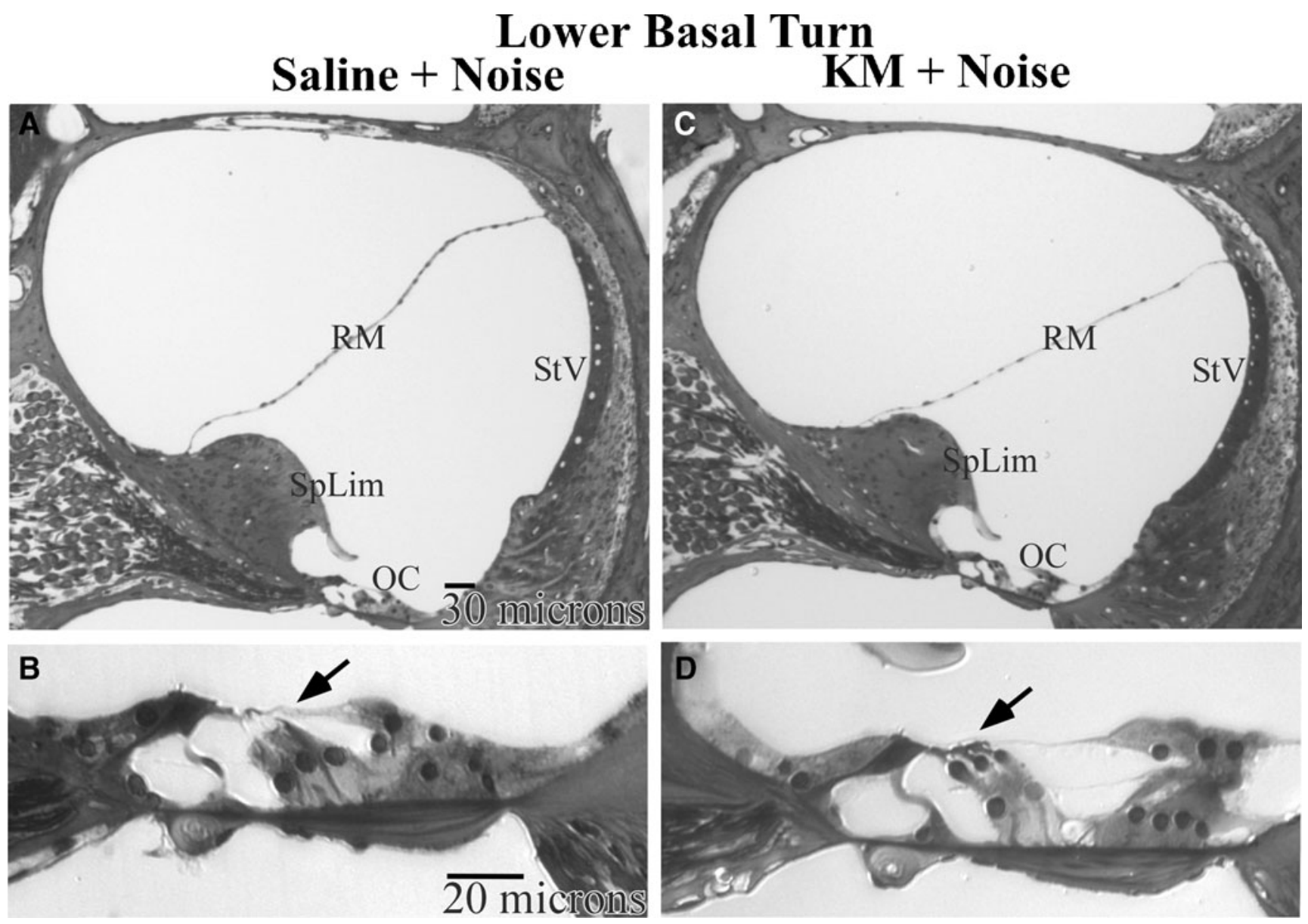

FIG. 6. Light photomicrograph of the cochlear lower base ( $\sim 40 \mathrm{kHz}$ region) in the same example mice depicted in Figure 5, receiving Saline + Noise (A, B) or $\mathrm{KM}+$ Noise (C, D). The sole clear distinguishing feature is the absence of outer hair cells in the saline-treated animal (arrows in B, D). StV Stria vascularis; RM Reissners membrane; SpLim spiral limbus; OC organ of Corti.

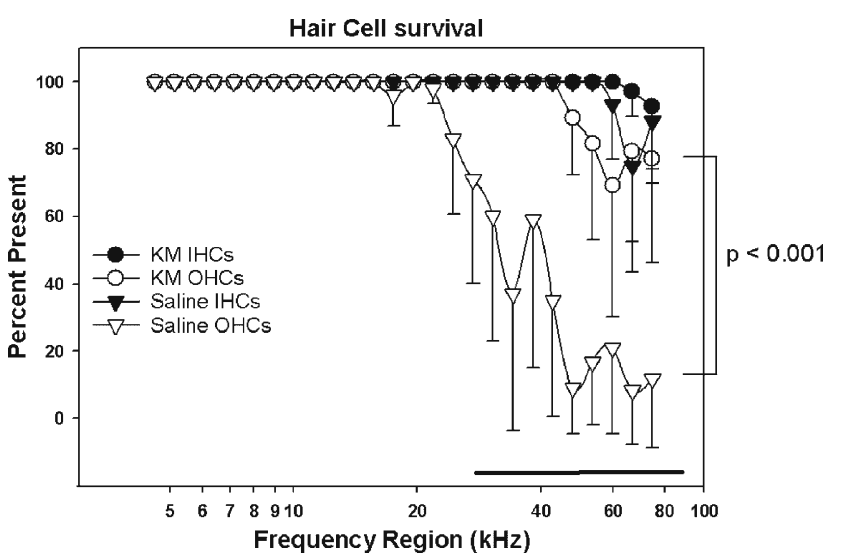

FIG. 7. Mean $(-\mathrm{SD})$ cochleograms for $\mathrm{KM}+$ Noise and Saline + Noise groups ( $N=7$ each). Outer hair cell losses differed significantly by treatment, extending on average $\sim 2.6 \mathrm{~mm}$ from the base in controls, but only $\sim 1.2 \mathrm{~mm}$ from the base in KM-treated mice. Losses of inner hair cells were modest and did not clearly vary by treatment. Horizontal bar indicates specific locations where $\mathrm{OHC}$ counts differed significantly $(p<.032)$ by treatment, as indicated by Bonferroni multiple comparisons tests. loss. KM-treated mice also showed OHC loss, yet only extending about $1.2 \mathrm{~mm}$ from the base. This appears consistent with the suggested trend toward hearing loss at $40 \mathrm{kHz}$ in these mice (Fig. 1). Both treatment groups showed similar modest IHC loss within the cochlear hook region.

The finding of normal thresholds in mice receiving KM alone (Fig. 2) indicated that the KM dose applied was sub-toxic. Nevertheless, since the cochlear base is most vulnerable to ototoxins, we considered whether the modest hair cell loss in the cochlear hook region of KM-treated mice might be due to KM, and not noise. Examination of three cochleas from mice receiving KM without noise (not shown) revealed partial loss of OHCs spanning much of the hook region in one animal. Such loss is atypical of young CBA/J mice. Notably, however, two of seven mice receiving both KM and noise showed no hair cell loss. Combined with threshold data (Figs. 1 and 2), the evidence suggests that hair cell loss in the basal tip of some KM + Noise animals may have been caused by KM itself, but more often probably represented residual noise injury. 


\section{DISCUSSION}

\section{Summary of findings}

No synergistic effect increasing NIPTS was found for mice treated with both kanamycin and noise. Instead, mice treated with a sub-chronic, low dose of kanamycin prior to noise exposure were paradoxically protected from NIPTS, showing ABR thresholds not significantly different from unexposed controls. The protected mice correspondingly showed significant preservation of OHCs in the basal half of the cochlea compared to saline controls. Kanamycin alone had no effect on ABR thresholds immediately following treatment (that is, at the time noise exposure occurred) or at the termination of experiments (Fig. 2). These findings argue against an acute hearing loss at the time of noise exposure, which could have potentially provided a degree protection against NIPTS. They also argue against any permanent effect of the KM treatment on thresholds, although we could not rule out that some hair cell loss in the extreme base was KM-related. A single dose of KM prior to noise was not protective; thus, the mere presence of kanamycin at the time of noise exposure was not sufficient to provide protection (Fig. 3). This result argues against any protective mechanisms that require only the presence of KM, such as plugging of transducer channels (Marcotti et al. 2005), thereby reducing active force generation by OHCs. Animals in the Saline + Noise group were not protected from NIPTS (Fig. 4). Therefore, protection afforded by the stress of handling and injection, potentially mediated by glucocorticoids (Wang and Liberman- did not appear to be a significant factor. Additional experiments in which the interval between the final KM dose and noise exposure was extended further indicated that KM's protective effects continue at least $48 \mathrm{~h}$ from the end of the dosing regimen. A corollary of the latter observation is that less rigorous dosing paradigms than the one we tested may be equally effective against similar exposures.

\section{Noise vulnerability in $\mathrm{CBA} / \mathrm{J}$}

Our original hypothesis called for an experimental paradigm involving subclinical levels of both noise and KM. While the chosen KM regimen appeared subclinical in most cases, exposure to $30 \mathrm{~s}$ of noise produced moderate NIPTS and hair cell loss in the young $\mathrm{CBA} / \mathrm{J}$ mice. This was not an anticipated outcome, although it produced the benefit of a large NIPTS that uncovered KM-related protection. Previous research comparing the noise susceptibility of mice (CBA/CaJ, C57BL/6J, BALB/cJ) aged 1-2 and 5-7 months (Ohlemiller et al. 2000) determined NIPTS "threshold" for exposure duration of $3.4 \mathrm{~min}$ for young $\mathrm{CBA} / \mathrm{CaJ}$ mice using the same noise applied here. Based on this result, it was presumed that young CBA/Js would show a noise dose-response pattern similar to the $\mathrm{CBA} / \mathrm{CaJ}$ and that $30 \mathrm{~s}$ of noise would produce no NIPTS. CBA/CaJ and CBA/J mice are often treated as interchangeable for purposes of hearing studies. The present noise work, along with a recent comparison of aging $\mathrm{CBA} / \mathrm{J}$ and $\mathrm{CBA} / \mathrm{CaJ}$ (Ohlemiller 2009), suggests this is not the case. The surprising noise vulnerability of young $\mathrm{CBA} / \mathrm{J}$, which we describe elsewhere (Rybak Rice et al. 2009), contrasts with a lack of any notable susceptibility to kanamycin (Wu et al. 2001). The extent of NIPTS and hair cell loss in the young CBA/Js strongly suggest our $\mathrm{KM}$ results are not limited to an "unchallenging" noise or to noise that only causes a temporary threshold shift. In fact, the extent of both NIPTS and hair cell loss in these mice exceeded those produced by $2 \mathrm{~h}$ of similar noise in older CBA/J mice (Ohlemiller and Gagnon 2007). It is possible that the present results are closely tied to some unusual characteristic of young $\mathrm{CBA} / \mathrm{Js}$.

\section{Cells impacted by noise and protected by KM}

The only clear anatomic difference that distinguished the KM-protected mice from saline controls was the extent of OHC loss (Fig. 7). Both groups of mice showed inner and outer hair cell loss in the cochlear hook, a region not monitored by our highest ABR stimulus frequency $(40 \mathrm{kHz})$. OHC loss in KM-treated mice also extended into the lower base so that essentially all NIPTS in these mice could be accounted for in terms of hair cell loss. Within saline controls, OHC loss extended apically to regions serving the three highest ABR test frequencies (20, $28.3,40 \mathrm{kHz}$ ). The most parsimonious explanation for NIPTS in these mice was, therefore, OHC loss in the lower base and subtle OHC injury more apically. Within the cochlea, aminoglycosides preferentially injure the stria vascularis and outer hair cells (Taylor et al. 2008; Rizzi and Hirose 2007; Forge and Schacht 2000). Although noise can also injure the stria, the injury appears largely reversible under all but the most extreme conditions (Ohlemiller and Gagnon 2007; Hirose and Liberman 2003), and it is not clear that lateral wall events can ultimately impact the extent of NIPTS (Ohlemiller 2008). Since OHC function and survival represent the most salient common target of both noise and KM, we suggest that preservation of $\mathrm{OHC}$ function and survival constitutes the most likely locus of KM-related protective mechanisms and that KM engages protective cascades within OHCs. Recent studies in young mice (Wu et al. 2001; Wang and Steyger 2009) indicate that significant levels of KM would have been present in 
both cochlear fluids and hair cells at the time of our noise exposure. Aminoglycosides may enter hair cells from either endolymph or perilymph and may require $24 \mathrm{~h}$ to be cleared (Wang and Steyger 2009; $\mathrm{Li}$ and Steyger 2009). Thus, significant levels of KM were likely maintained and probably increased over the course of treatment. Even a single KM dose, which we found not to be protective (Fig. 3), should have yielded "therapeutic" levels within the organ of Corti $1 \mathrm{~h}$ later. The lack of efficacy in this case argues for an innate protective response to $\mathrm{KM}$ that activates with some delay. Whether any single dose paradigm may be protective is under study.

\section{Sub-chronic kanamycin as a form of preconditioning}

Sub-chronic low-dose application of kanamycin likely engages innate protective mechanisms and thus may be added to the ranks of preconditiong stressors. Preconditioning refers to a mildly injurious event that confers protection against a later, more injurious, event (Gidday 2006; Dirnagl et al. 2003; Eisen et al. 2004; Ran et al. 2005). Demonstrated preconditioning inducers against NIPTS in mice include mild noise, heat stress, restraint, and hypoxia (Yoshida et al. 1999; Wang and Liberman 2002; Yoshida and Liberman 2000; Niu and Canlon 2002; Gagnon et al. 2007). Two studies have reported partial protection in guinea pigs by amikacin or gentamicin against later, high-dose, application of the same ototoxins (De Oliveira et al. 2004; Maudonnet et al. 2008). Many pathways and processes have been implicated in preconditioning, including improved blood flow, increased glucocorticoid levels, enhanced antioxidant protections, and increased production of heat shock proteins. Those that participate in the protection demonstrated here remain to be determined. KM affects multiple organs (Henley and Rybak 1995; Rizzi and Hirose 2007; Forge and Schacht 2000), where it may also elicit protective cascades, so that systemically mediated preconditioning influences cannot presently be ruled out.

The principles of preconditioning link a subinjurious event to protection against a later injurious event. Very likely, there exists a tradeoff between the severity of the initial event and the extent of later protection. Our effective KM dose may have caused some OHC loss and thus may not have been sub-toxic in every case. While we have not yet probed the limits of the protection against NIPTS afforded by KM, it is possible that KM-related injury and protection are causally related. It may, for example, be possible to find circumstances and models in which increasing protection against NIPTS at mid and low frequencies is positively linked to elevated thresholds and hair cell loss in the deep cochlear base.

\section{Kanamycin in the early vulnerability window}

An early window of heightened vulnerability has been found in animals to apply to noise injury as well as a variety of ototoxins. The targets of this early magnified injury show only partial overlap: Ototoxins primarily impact hair cells and stria (Bernard 1981; Lataye et al. 2004; Pryor et al. 1984; Rybak et al. 1991; Henley and Rybak 1995), while noise preferentially targets hair cells and neurons (Henley and Rybak 1995; Falk et al. 1974; Ohlemiller et al. 2000; Kujawa and Liberman 2006). The window of vulnerability also need not be the same for noise versus aminoglycosides (Henry et al. 1981; Henry 1983) or even for all ototoxicants (e.g., Lataye et al. 2004). The existence of somewhat different targets and timeframes for noise and ototoxic injury suggests that these operate at least partially independently. We know of no other study demonstrating a protective effect of kanamycin or any other ototoxin against NIPTS. Instead, many studies have shown exacerbation of NIPTS by aminoglycosides in animals (e.g., Bombard et al. 2005; Dayal et al. 1971; Dayal and Barek 1975; Marques et al. 1975; Hawkins et al. 1975; Ryan and Bone 1978; Brown et al. 1980; Brummett et al. 1992). This effect has, therefore, been predicted for humans and anticipated to be enhanced in human infants (see Li and Steyger 2009). The prediction of amplified synergistic interactions early in life has found some support in animal studies (Dodson et al. 1982) but, to date, no direct support in humans (see citations in $\mathrm{Li}$ and Steyger 2009). The robustness of the protection we find in young CBA/J mice may mean that at least for low KM doses, the true nature of $\mathrm{KM} /$ noise interactions during the early window is just the opposite of predicted outcomes. A general protective effect might reflect distinct characteristics of protective cascades early in life and may even be causally related to the very factor(s) that underlie the early vulnerability window.

The present findings may hold implications for which treatments in medically fragile human neonates pose extra risks and which do not. Once uncovered, the protective pathways that kanamycin engages may offer new pharmacologic interventions, both during the early vulnerability window and later. Should our findings ultimately prove limited to particular mouse models, it should be possible using standard genetic approaches to identify critical genes and pathways. These genes may provide insights into the nature of injury and innate protection during the early window and could lead to genetic tests for individual risk. 


\section{ACKNOWLEDGEMENTS}

Thanks to M. Rybak Rice and A. Rosen for technical assistance and to Dr. K. Hirose for critical comments; supported by P30 DC004665 (R. Chole), P30 NS057105 (D. Holtzman), R01 DC03454 (KKO), R01 DC08321 (KKO), WUSM Department of Otolaryngology.

\section{REFERENCES}

BERNARD PA (1981) Freedom from ototoxicity in aminoglycoside treated neonates: a mistaken notion. Laryngoscope 91 (12):1984-1994

Bombard F, Campo P, Lataye R (2005) Combined effects of noise and gentamicin on hearing in the guinea pig. Noise Health 7:20 39

Brown JJ, Brummett RE, Fox KE (1980) Combined effects of noise and kanamycin: cochlear pathology and pharmacology. Arch Otolaryngol 106:744-750

BrummetT RE, Fox KE, Kempton B (1992) Quantitative relationships of the interaction between sound and kanamycin. Arch Otolaryngol Head Neck Surg 118:498-500

Buckland L, Austin N, Jackson A, Inder T (2003) Excessive exposure of sick neonates to sound during transport. Arch Dis Child Fetal Neonatal Ed 88:513-516

Chen CS, Aberdeen GC (1980) Potentiation of noise-induced audiogenic seizure risk by salicylate in mice as a function of salicylate-noise exposure interval. Acta Otolaryngol 90:61-65

Chen CS, Saunders JC (1983) The sensitive period for ototoxicity of kanamycin in mice: morphological evidence. Arch Otolaryngol 238(3):217-223

DAYAL VS, BAREK WG (1975) Cochlear changes from noise, kanamycin, and aging II: Potentiating effects of noise and kanamycin. Laryngoscope 85(1):8-11

Dayal VS, Kokshanian A, Mitchell DP (1971) Combined effects of noise and kanamycin. Ann Oto Rhinol Laryngol 80:897-902

De Oliveira JAA, Canedo DM, Rossato M, De Andrade H (2004) Selfprotection against aminoglycoside ototoxicity in guina pigs. Otolaryngology-Head and Neck Surgery 131:271-279

Dirnagl U, Simon RP, Hallenbeck JM (2003) Ischemic tolerance and endogenous neuroprotection. TINS 26:248-254

Dodson HC, Bannister LH, DoukK EE (1982) The effects of combined gentamicin and white noise on the spiral organ of young guinea pigs. Acta Otolaryngol 94:193-202

Eisen A, Fisman EZ, Rubenfire M, Freimark D, McKechnie R, Tenenbaum A, Motro M, Adler Y (2004) Ischemic preconditioning: nearly two decades of research. A comprehensive review. Atherosclerosis 172:201-210

Falk SA, Cook RO, Haseman JK, Sanders GM (1974) Noise-induced inner ear damage in newborn and adult guinea pigs. Laryngoscope 84:444-453

Forge A, Schacht J (2000) Aminoglycoside antibiotics. Audiol Neuro-Otol 5:3-22

Gagnon PM, Simmons DD, Bao J, Lei D, Ortmann AJ, Ohlemiller KK (2007) Temporal and genetic influences on protection against noise-induced permanent threshold shift by hypoxic preconditioning in mice. Hear Res 226:79-91

GIDDAY JM (2006) Cerebral preconditioning and ischaemic tolerance. Nature Rev Neurosci 7:437-448

Hawkins JE Jr, Marques DM, Clark CS, Preston RE (1975) Ototoxic potentiation between ethacrynic acid and aminoglycoside antibiotics in guinea pigs. J Acoust Soc Am Suppl 57:60

Henley C, RyBak LPM (1995) Ototoxicity in developing animals. Brain Res Rev 20:68-90
Henry KR (1983) Lifelong susceptibility to acoustic trauma: changing patterns of cochlear damage over the life span of the mouse. Audiology 22:372-383

Henry KR, McGinn MD (1992) The mouse as a model for human audition: a review of the literature. Audiology 31:181-189

Henry KR, Chole RA, McGinn MD, Frush DP (1981) Increased ototoxicity in both young and old Mice. Arch Otolaryngol 107:92-95

Hirose K, Liberman MC (2003) Lateral wall histopathology and endocochlear potential in the noise-damaged mouse cochlea. J Assoc Res Otolaryngol 4:339-352

Humes LE (1984) Noise-induced permanent threshold shift as influenced by other agents and by some physical characteristics of the individual. J Acoust Soc Am 76(5):1318-1329

Kujawa SG, Liberman MC (2006) Acceleration of age-related hearing loss by early noise: evidence of a misspent youth. J Neurosci 26:2115-2123

Lataye R, Pouyatos B, Campo P, Lambert A-M, Morel G (2004) Critical period for styrene ototoxicity in the rat. Noise Health $7: 1-10$

Li H, Steyger PS (2009) Synergistic ototoxicity due to noise exposure and aminoglycoside antibiotics. Noise Health 11:26-32

Marcotti W, van NetTen SM, KRos CJ (2005) The aminoglycoside antibiotic dihydrostreptomycin rapidly enters mouse outer hair cells through the mechano-electricl transducer channels. J Physiol 567:505-521

Marques DM, Clark CS, Hawkins JE JR (1975) Potentiation of cochlear injury by noise and ototoxic antibiotics in guinea pigs. J Acoust Soc Am Suppl 57(S1):S60

Maudonnet EN, De Oliveira JAA, Rossato M, Hyppolito MA (2008) Gentamicin attenuates gentamicin-induced ototoxicity-self protection. Drug Chem Toxicol 31:11-25

Muller M, von Hunerbein K, Hoidis S, Smolders JWT (2005) A physiological place-frequency map of the cochlea in the CBA/J mouse. Hear Res 202:63-73

Niu X, Canlon B (2002) Protective mechanisms of sound conditioning. Adv Otorhinolaryngol 59:96-105

Mehl AL, Thomson V (1998). Newborn hearing screening: the great omission. Pediatrics 101(1) URL: http://www.pediatrics.org/ cgi/content/full/101/1/e4

OHLEMILLER KK (2006) Contributions of mouse models to understanding of age- and noise-related hearing loss. Brain Res 1091: 89-102

OHLEMILLer KK (2008) Recent findings and emerging questions in cochlear noise injury. Hear Res 245:5-17

OHLemiller KK (2009) Mechanisms and genes in human strial presbycusis from animal models. Brain Res 1277:70-83

Ohlemiller KK, GAGNON PM (2007) Genetic dependence of cochlear cells and structures injured by noise. Hearing Res 224:34-50

Ohlemiller KK, Wright JS, HeIDbreder AF (2000) Vulnerability to noise-induced permanent threshold shift in 'middle-aged' and young adult mice: a dose-response approach in CBA, C57BL, and BALB inbred strains. Hear Res 149:239-247

Pryor GT, Dickinson J, Feeney E, Rebert CS (1984) Hearing loss in rats first exposed to toluene as weanlings or as young adults. Neurobehav Toxicol Teratol 6:111-119

Pujol R (1992) Sensitive developmental period and acoustic trauma: facts and hypotheses. In: Dancer AL (ed) Noise-induced hearing loss. Mosby, St. Louis, pp 196-203

Ran R, Xu H, Lu A, Bernaudin M, Sharp FR (2005) Hypoxic preconditioning in the brain. Dev Neurosci 27:87-92

Rizzi MD, Hirose K (2007) Aminoglyciside ototoxicity. Curr Opin Otolaryngol Head Neck Surg 15:352-357

Ryan A, Bone RC (1978) Potentiation of kanamycin ototoxicity by a history of noise exposure. Trans Am Acad Opthalmol Otolaryngol 86:125-128

Rybak LP, Whitworth C, Scott V, Weberg A (1991) Ototoxicity of furosemide during development. Laryngoscope 101:1167-1174

Rybak Rice ME, Gagnon PM, Ohlemiller KK (2009) Divergence of noise vulnerability in CBA/J and CBA/CaJ mice. Abstr Assn Res Otolaryngol 32:45 
SHENAI JP (1977) Sound levels for neonates in transit. Journal of Pediatrics 90(5):811-812

Skeoch CH, Wilson AM, Boоth P (2005) Fit to fly: practical challenges in neonatal transfers by air. Arch Dis Child Fetal Neonatal Ed 90:456-460

Taylor RR, Nevill G, Forge A (2008) Rapid hair cell loss: A mouse model for cochlear lesions. J Assoc Res Otolaryngol 9:44-64

WANG Y, Liberman MC (2002) Restraint stress and protection from acoustic injury in mice. Hearing Res 165:96-102

Wang Q Steyger PS (2009) Trafficking of systemic fluorescent gentamicin into the cochlae and hair cells. J Assoc Res Otolaryngol 10:205-219
Wu W-J, Sha S-H, McLaren JD, Kawamoto K, Raphael Y, Schacht J (2001) Aminoglycoside ototoxicity in adult CBA, C57BL, and BALB mice and the Sprague-Dawley rat. Hear Res 158:165-178

Yoshida N, Liberman MC (2000) Sound conditioning reduces noiseinduced permanent threshold shift in mice. Hearing Res 148:213-219

Yoshida N, Kristiansen A, Liberman MC (1999) Heat stress and protection from permanent acoustic injury in mice. J Neurosci 19:10116-10124

Zheng QY, Johnson KR, ERwAY LC (1999) Assessment of hearing in 80 inbred strains of mice by ABR threshold analysis. Hear Res 130:94-107 